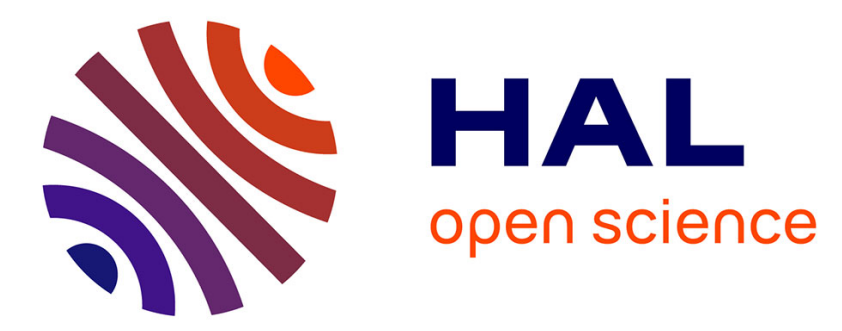

\title{
The Preseismic and Postseismic Phases of the 700-km Deep M7.9 Bonin Islands Earthquake, Japan
}

\author{
B. Gardonio, A. Schubnel, S. Das, H Lyon-Caen, D. Marsan, M. Bouchon, A.
}

Kato

\section{- To cite this version:}

B. Gardonio, A. Schubnel, S. Das, H Lyon-Caen, D. Marsan, et al.. The Preseismic and Postseismic Phases of the 700-km Deep M7.9 Bonin Islands Earthquake, Japan. Geophysical Research Letters, 2020, 47 (1), 10.1029/2019GL085589 . hal-02940068

\section{HAL Id: hal-02940068 \\ https://hal.science/hal-02940068}

Submitted on 16 Sep 2020

HAL is a multi-disciplinary open access archive for the deposit and dissemination of scientific research documents, whether they are published or not. The documents may come from teaching and research institutions in France or abroad, or from public or private research centers.
L'archive ouverte pluridisciplinaire HAL, est destinée au dépôt et à la diffusion de documents scientifiques de niveau recherche, publiés ou non, émanant des établissements d'enseignement et de recherche français ou étrangers, des laboratoires publics ou privés. 


\section{Geophysical Research Letters}

\author{
RESEARCH LETTER \\ 10.1029/2019GL085589 \\ Key Points: \\ - We present the first evidence of \\ intense foreshock activity before a \\ deep-focus earthquake \\ - 49 newly detected EQs reveal slab \\ geometry and the possible existence \\ of metastable olivine wedge at depth \\ - We find a low productivity aftershock \\ sequence that follows Omori's law
}

Supporting Information:

- Supporting Information S1

- Data Set S1

- Data Set S2

Correspondence to:

B. Gardonio,

gardonio@geologie.ens.fr

Citation:

Gardonio, B., Schubnel, A., Das, S., Lyon-Caen, H., Marsan, D.,

Bouchon, M., \& Kato, A. (2020). The preseismic and postseismic phases

of the $\sim 700-\mathrm{km}$ deep $\mathrm{M}_{w} 7.9$

Bonin Islands earthquake, Japan.

Geophysical Research Letters, 47,

e2019GL085589. https://doi.org/10.

1029/2019GL085589

Received 1 OCT 2019

Accepted 5 DEC 2019

Accepted article online 9 DEC 2019

(C)2019. American Geophysical Union. All Rights Reserved.

\section{The Preseismic and Postseismic Phases of the $\sim 700-\mathrm{km}$ Deep $\mathbf{M}_{w} 7.9$ Bonin Islands Earthquake, Japan}

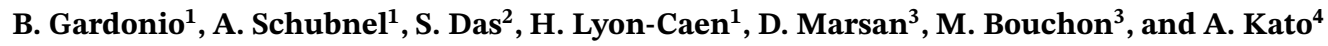 \\ ${ }^{1}$ Laboratoire de Géologie, Departement de Géosciences, École Normale Supérieure, CNRS UMR 8538, PSL Research \\ University, Paris, France, ${ }^{2}$ Department of Earth Sciences, University of Oxford, Oxford, UK, ${ }^{3}$ CNRS, IRD, ISTerre, \\ Université Grenoble Alpes, Grenoble, France, ${ }^{4}$ Earthquake Research Institute, University of Tokyo, Bunkyo-ku, Tokyo, \\ Japan
}

Abstract The 30 May $2015 \mathrm{M}_{w}$ 7.9 Bonin Islands earthquake, Japan, is one of the largest deep-focus earthquakes ever recorded. Its occurrence, close to 700-km depth, in an area without any known historical seismicity, along with its magnitude, was a surprise to scientists. Deep earthquakes are generally believed to have few aftershocks and no foreshocks. Here, we explore the earthquake productivity in the hypocentral surroundings and detect 49 not previously identified earthquakes, 28 of which occurred during an accelerating preseismic phase that started 3 months prior to the main shock. This is the first time that such foreshock activity has been observed for a deep earthquake. The preseismic and postseismic activity suggests transformational faulting within a metastable olivine wedge (MOW) inside the slab at depth as the triggering principal mechanism for this deep earthquake sequence, the seismicity starting where the backward bending of the subducting Pacific plate is maximum.

Plain Language Summary Deep earthquakes have been puzzling seismologists for almost a century, since their discovery in the 1920s. Earthquakes deeper than $50 \mathrm{~km}$ represent about $25 \%$ of the global seismicity, and deep-focus earthquakes are defined as those located at 300-km depth or more. They can be exceedingly large and occur at temperatures and pressures where sliding and fracture are inhibited, thus the brittle fracture/friction mechanism, valid in Earth's crust, cannot hold. Despite their abundance, the physical mechanism behind deep-focus earthquakes is still a subject of ongoing debate. The Bonin Islands earthquake (30 May 2015, $\mathrm{M}_{w}$ 7.9) occurred at 680-km depth in a previously quiet area. In order to better understand why and how it occurred there, we searched for previously unknown earthquakes in the surroundings. For the first time, we identify a preseismic phase preceding such a very deep-focus earthquake. The location of the newly detected earthquakes reveals the geometry of the slab at depth, and their spatiotemporal distribution supports transformation of metastable olivine as the rupture initiation process.

\section{Introduction}

The $\mathrm{M}_{w} 7.9\left(M_{j m a} 8.1\right)$ Bonin Islands, Japan, earthquake occurred on 30 May 2015 at a depth of $680 \mathrm{~km}$ (Figure 1) in a previously seismically quiet area (symbols for magnitudes used in the paper are explained in the Supporting Information Text S1). Analysis of broadband seismograms revealed a hypocenter located below $660-\mathrm{km}$ depth; the $660-\mathrm{km}$ discontinuity may be deflected towards greater depths in this region (Kuge, 2017). The earthquake is located in the cold portion of a subducting oceanic lithosphere of complex geometry (Obayashi et al., 2017; Zhao et al., 2017). Its Global Centroid Moment Tensor (GCMT) focal mechanism indicates that one of the planes has a dip of $25^{\circ}$ (Figures 1 and 6), which is common for deep-focus earthquakes (Frohlich, 2006). According to the Japanese Meteorological Agency (JMA), the earthquake triggered only four aftershocks, an expected result since the aftershock productivity of deep-focus earthquakes is systematically lower than that of shallow ones for comparable magnitude (Frohlich, 2006; Frohlich \& Willemann, 1987; Kagan \& Knopoff, 1980; Persh \& Houston, 2004; Vallée, 2013). This is one of the many unusual properties of deep-focus earthquakes relative to crustal ones, with implications for the mechanics of the earthquake process.

Due to the extreme pressure and temperature conditions at these depths, the mechanics at play during deep-focus earthquake nucleation and propagation have been vigorously debated (Frohlich, 2006) since 


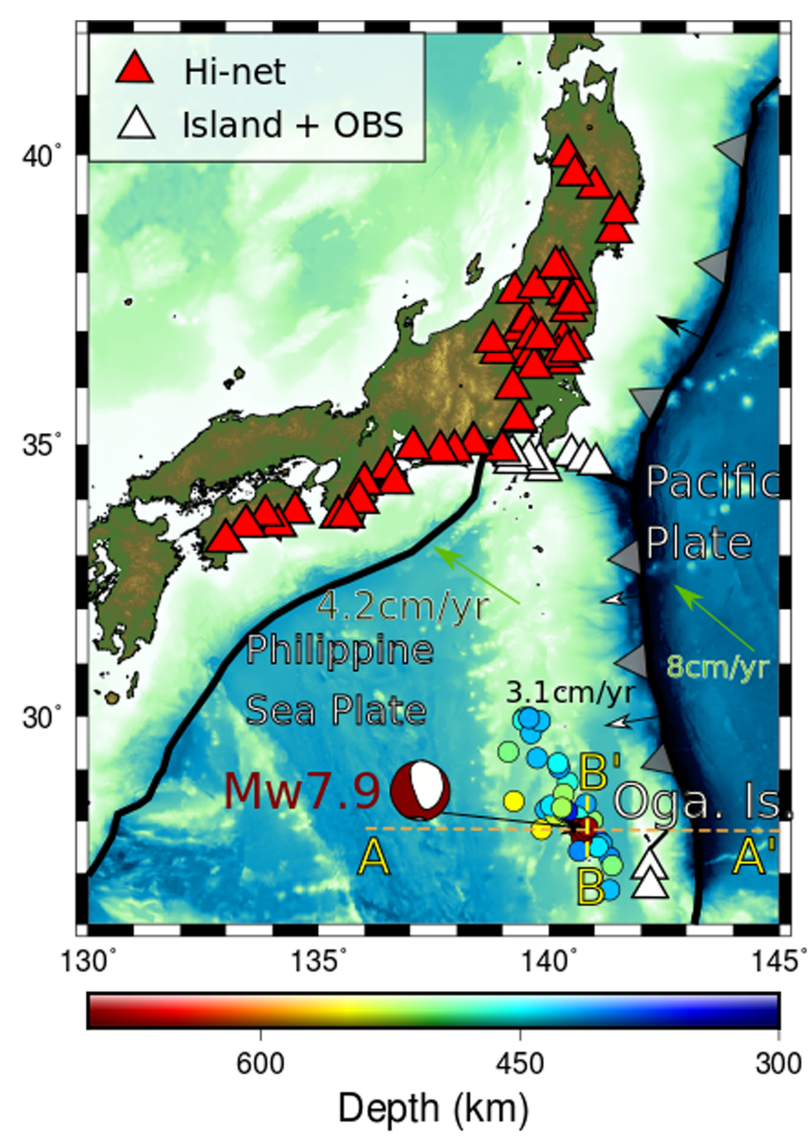

Figure 1. The Japanese subduction zone and location of the 2015 deep Bonin Islands earthquake. Red and white triangles are stations from the Hi-net network and islands or OBS stations, respectively (note that there are three stations on the Ogasawara island, marked Oga. Is.). The dots show the JMA location of the seismicity, color coded with depth. The plate and trench velocities are shown in green and black, respectively (from Schellart et al., 2007). Lines $\mathrm{AA}^{\prime}$ and $\mathrm{BB}^{\prime}$ indicate the location of the cross sections of Figure 6. The focal mechanism is the Global Centroid Moment Tensor (GCMT) point-source solution of the 30 May $2015 M_{w} 7.9\left(M_{j m a} 8.1\right)$ main shock.

their discovery about a century ago (Turner, 1922; Wadati, 1927). Two plausible mechanisms have been invoked: (i) transformational faulting (Green II \& Burnley, 1989; Kirby, 1987), that is, faulting instabilities associated with the transformation of cold metastable olivine into its denser spinel-type crystalline structures, and (ii) grain size reduction and enhanced plastic flow of olivine crystal grains leading to a self-sustained shear-heating thermal runaway (Kelemen \& Hirth, 2007). Both mechanisms (i) and (ii) could eventually lead to frictional melting (Kanamori et al., 1998). Experimental studies supporting transformational faulting (Green II \& Burnley, 1989; Schubnel et al., 2013) suggest that laboratory analogs of deep-focus earthquakes might be preceded by an increasing number of earthquakes of increasingly larger magnitudes (Wang et al., 2017), just as large shallow earthquakes can be preceded by foreshocks both in the field (Bouchon et al., 2011; Bouchon et al., 2013; Ellsworth \& Beroza, 1995; Kato et al., 2012; Kato \& Nakagawa, 2014; Radiguet et al., 2016) and in the laboratory (McLaskey \& Lockner, 2014; Passelègue et al., 2014). On the contrary, the precursor to a shear-heating thermal runaway type of instability should be a ductile aseismic type of phenomenon (Kelemen \& Hirth, 2007). Investigating whether the absence of foreshocks is a real characteristic of large deep-focus earthquakes thus has crucial implications for the understanding of the mechanics at work during such events. In this study, we used a Waveform Matched-Filter Technique: an effective method to detect missing earthquakes hidden in the signal of larger ones or in the noise (Gibbons \& Ringdal, 2006; Peng \& Zhao, 2009; Shelly et al., 2007) to better constrain the spatial and temporal evolution of the seismicity in the immediate surroundings of the main shock hypocenter before and after the earthquake. 


\section{Materials and Methods}

\subsection{Computing Coherency}

The Waveform Matched-Filter Technique is based on the computation of the similarity between a window that contains the template, A, and the continuous signals, B. To do so, we compute the coherency value (C) in the frequency domain (equation (1), Gardonio et al., 2018). The template window starts $2 \mathrm{~s}$ before the $\mathrm{P}$ wave arrival and lasts $10 \mathrm{~s}$. Coherency is calculated by sliding the 10-s template over the continuous signal in 2-s increments. The windows are tapered by a Hanning window.

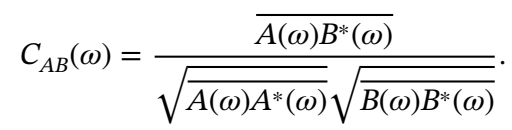

The overbar denotes averaging over four consecutive (discrete) frequency values centered on frequency $\mathrm{f}=\omega /(2 * \pi)$ and $A^{*}$ defines the complex conjugate of A.

The main shock was followed by four aftershocks according to the JMA catalog (Figure S1). We used these five earthquakes as templates on the vertical component of 46 stations of the Hi-net network, 8 stations located on islands, and 3 ocean bottom seismometers (OBS; Figure 1, Data Set S1). We applied the Waveform Matched-Filter Technique over 6 months of continuous data (from February to July 2015).

We chose stations on the southwest and northeast of Japan in order to have the best possible azimuthal coverage. Because high-frequency seismic energy can be trapped in the slab in the case of deep-focus earthquakes (Furumura \& Kennett, 2005; 2017), the seismic signals were strong enough for the stations in the northeast of Japan to record them.

We calculate $C_{A B}$, the mean coherency for three frequency bands: $1-4,2-5$, and 2-8 Hz. We keep the highest coherency value among them and remove multiple detections of the same earthquake by taking the maximum coherency in a 30-s sliding window.

\subsection{Selection of Possible Detections}

One computing task consists of the coherency computation between a template and 1 day of continuous signal. For each task, we apply a selection criterion of $C_{A B} \geq \operatorname{mean}\left(C_{A B}\right)+5 * \sigma\left(C_{A B}\right)$, with $\sigma$ being the standard deviation (Lengliné et al., 2012). An example of the distribution of the coherency for one task (i.e., one template over 1 day of continuous recordings) and the corresponding threshold is given in Figure S2.

The detected earthquakes are somewhat hidden in the noise level (Figure 2). For example, the detection on 10 February 2015 at $16 \mathrm{~h} 12$ (the date and time are given in Japanese time) is hidden in the noise, whereas detection on 6 February 2015 at $13 \mathrm{~h} 05$ is more visible in the continuous signal. We aligned the waveforms to stack them (Figure 2, bottom). The result of the stack allows us to retrieve the P wave arrival of the template. Furthermore, we computed the coherency between the continuous signal on the horizontal component and the $\mathrm{S}$ wave of the template and stacked the waveforms (Figure S3). We also retrieve the S waves and manage to visually isolate their arrivals even though the signal is more noisy than for $\mathrm{P}$ waves. It is to be noted that several earthquakes were detected by more than one template and that the main shock also detected earthquakes (Figure S4). An example of a detection by the main shock is given in Figure S5. Only earthquakes detected by at least four stations, including one on the Ogasawara Island, are listed in the output catalog.

\subsection{Location of the Detected Earthquakes}

As a first step of the location process we compare the arrival times of the detected earthquake $(d)$ with the arrival times of the template $(x)$ that detected it, taking the first arrival time as the reference. If the difference between the arrival times matrices is small, then the two earthquakes should be located close together (Figure S6).

To do so, we need the exact time of detection of the earthquakes and thus computed the coherency on a 1-s sample sliding window (instead of $2 \mathrm{~s}$ ). We then searched for the maximum coherency value and the minimum delay between the template and the detected earthquake to obtain the precise time of detection for every station that detected it. This allowed us to compare the arrival time matrices (in seconds) as follows:

$$
D_{t}=\frac{\sqrt{\sum_{i=1}^{N_{s t a}}\left(\left(t_{x i}-t_{x r e f}\right)-\left(t_{d i}-t_{d r e f}\right)\right)^{2}}}{N_{s t a}} .
$$




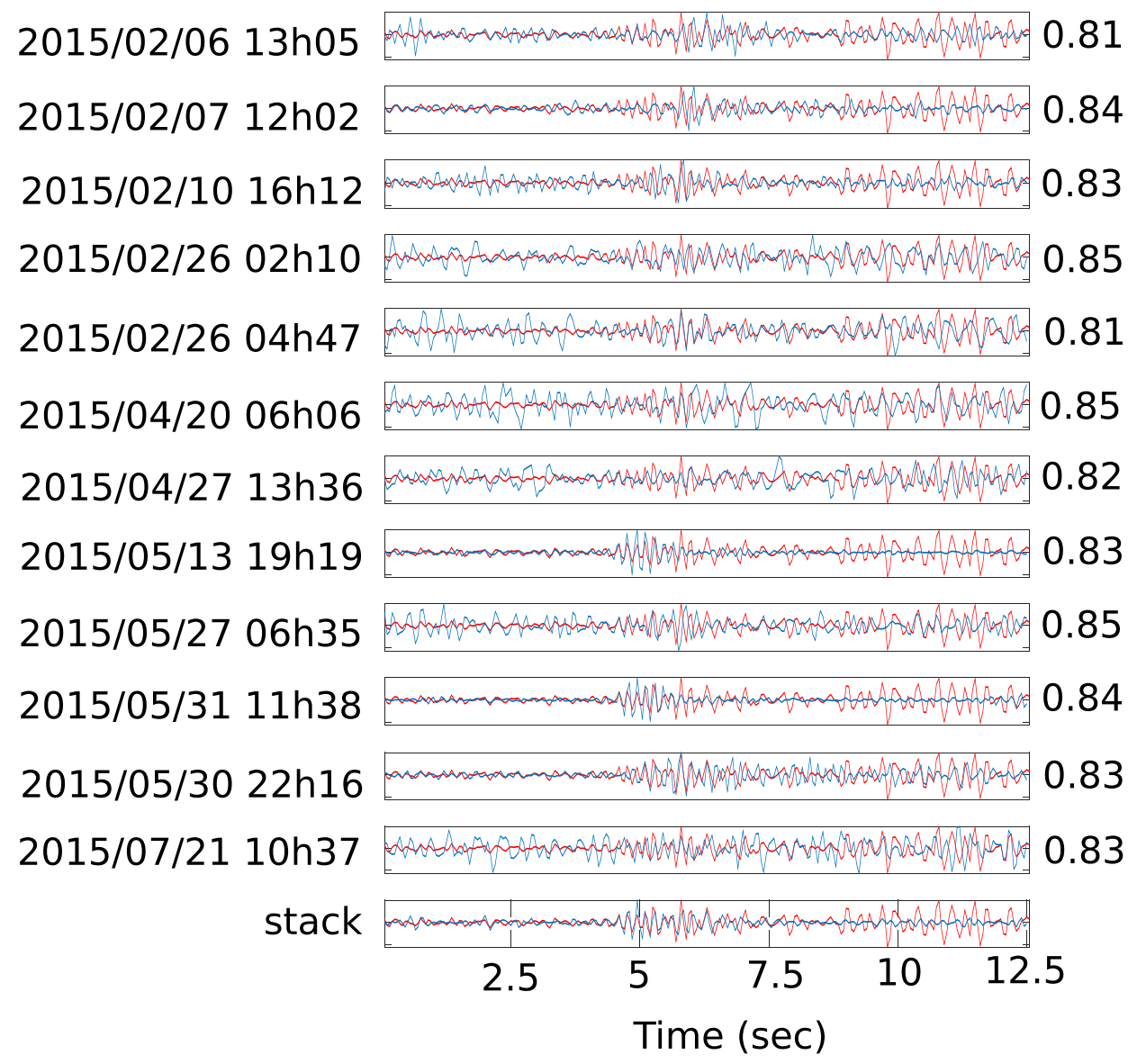

Figure 2. Example of detected earthquakes. The red trace shows the P wave of the $M_{j m a} 5.6$ template that occurred on the 3rd of June 2015 at 6H04 (Japanese time), recorded at JP.JCJ, on of the station located on the Ogasawara Island. The blue traces are the $\mathrm{P}$ waves of the detected earthquakes. The times of detection and coherencies are given on the left and right, respectively. The panel at the bottom gives the stack of all the detected earthquakes (in blue) that compares well with the arrival of the P wave template (in red). Note that the earthquake detected on 31 May 2015 at $11 \mathrm{~h} 38$ is not taken into account in the stack since its good signal to noise ratio could bias the result. Note that the energy rapidly decays after $10 \mathrm{~s}$ for the newly detected earthquakes, which might be due to attenuation, although it was not the case for the template that is a $M_{j m a} 5.6$ earthquake.

With $t_{x i}$ and $t_{d i}$ being the arrival time of the template and the detected earthquake, respectively, re $f$ is the arrival time at the reference station (the first arrival), and $N_{s t a}$ the total number of detecting stations. Then knowing the velocity model, we can use $D_{t}$ as a proxy to estimate the distance between the template and its detected earthquakes. Since the value of $D_{t}$ increases with distance to the templates, we can have a reasonable confidence in our location method (Figure S7). However, we took a step further in locating the earthquakes even though the geometry of the network and its location far away from the templates we used is a major impediment to deriving accurate locations.

We first relocated these five templates using the $\mathrm{P}$ wave arrival times of all the 58 stations used in this study and used these five relocated templates to locate the detected earthquakes, one after the other. The first step of the location procedure consists in defining the origin time of the detected earthquake $d$. The precise time of detection for every station that detected $d$ is used. We then hypothesized that the detected earthquake $d$ is located near its detecting template $x$ and used the travel time of $x$ to estimate the origin time of the detected earthquake. We did so for all the stations that detected the earthquakes and computed the mean origin time.

Two earthquakes (numbers 32 and 33 in our catalog) that we detect were not present in the JMA catalog but listed by the International Seismological Center (ISC; Willemann \& Storchak, 2001) (https://doi. org/10.31905/D808B830). In the following, we will use them to compare our results with the ISC catalog. According to the ISC, these two earthquakes occurred on 30 May 2015 at $22 \mathrm{~h} 16 \mathrm{mn} 17.46 \mathrm{~s}$ and on 31 
May 2015 at $11 \mathrm{~h} 38 \mathrm{mn} 26.05$. Using our method, their respective times of occurrence are $22 \mathrm{~h} 16 \mathrm{~m} 11.8 \mathrm{~s}$ and $11 \mathrm{~h} 38 \mathrm{mn} 24.38 \mathrm{~s}$. Figure S8 shows the distribution for the detected earthquake number 32 . In this example, the second of the origin time is between 9 and 12.5 with a mean of 11.82 . Figure S9 shows the different locations that result from using these different origin times; $3.5 \mathrm{~s}$ of difference corresponds to $10 \mathrm{~km}$ of distance between the different locations.

Then, the mean origin time is used to estimate the travel time of the newly detected earthquake. The last stage consists of computing a double difference relocation of the detected earthquakes using HypoDD (Waldhauser \& Ellsworth, 2000) and these travel times, hypothesizing that their first location is the location of the template that detected them. We used a $1 \mathrm{D}$ velocity model of 12 layers with a Vp/Vs ratio of $1.73 \mathrm{~km} / \mathrm{s}$ presented in Table S1.

\subsection{Location Uncertainty Estimation}

To test the robustness of our method, we applied it to the templates. This is possible because all the templates detected each other during the study. Here, we use only the inter-detection times (i.e., a template with other templates) and do not take into account the auto-detections (i.e., a template with itself). Figure S10 shows the location of the templates according to the JMA catalog, compared with the relative relocation using 1) HypoDD on the P-wave arrival times and 2) our method. Hypocenters of templates move by a maximum of 40, 20, and $12 \mathrm{~km}$ in longitude, latitude and depth, respectively. Our method shows the same deviation of the template locations except for the template number 2, which is located to the west.

Furthermore, our technique locates the earthquake number 32 at lat $=27.83^{\circ} \mathrm{N}$; lon $=140.65^{\circ} \mathrm{E}$; depth $=686 \mathrm{~km}$, while the ISC located it at lat $=27.99^{\circ} \mathrm{N}$; lon $=140.60^{\circ} \mathrm{E}$; depth $=700 \mathrm{~km}(22 \mathrm{~km}$ apart $)$. For the earthquake number 33 , our location is at lat $=27.80^{\circ} \mathrm{N}$; lon $=140.73^{\circ} \mathrm{E}$; depth $=677 \mathrm{~km}$, and the ISC locates it at lat $=27.79^{\circ} \mathrm{N}$; lon $=141.33^{\circ} \mathrm{E}$; depth $=700 \mathrm{~km}(57 \mathrm{~km}$ apart $)$.

Finally, we look at the difference between the $\mathrm{S}$ wave arrival times and $\mathrm{P}$ wave arrival $(T s-T p)$ times at station JP.JCJ (located on the Ogasawara Island). The templates have a $T s-T p$ time of $64 \mathrm{~s}$, and the detected earthquakes presented in the stacks indicate $T s-T p$ times spanning from 55 to $77 \mathrm{~s}$ (Figure S11).

\subsection{Magnitude Estimation}

To estimate the magnitude of the newly detected earthquakes, we used the relation defined in Lengliné et al. (2012): $m_{1}=m_{2}+1.35 \log _{10}(A 1 / A 2)$, with $m_{1}$ and $m_{2}$ as the earthquake magnitude of the detected earthquake and reference earthquake, respectively, and A their maximum amplitude. We compute $m_{1}$ for all the stations, using the main shock as the reference, and keep the mean value. The amplitude ratio is calculated over a 30-s long window, filtered between 2 and $8 \mathrm{~Hz}$. Since this relation was found for shallow earthquakes, we shall test its validity for deeper earthquakes on the four templates we used. We obtained magnitudes $\mathrm{M}$ of 5.0, 3.5, 5.3, and 3.8 compared to 5.1, 3.6, 5.6, and 3.8 in the JMA catalog. An example of this computation is given in Figure S12 to show the deviation of the magnitude value that we obtain for all the templates. Earthquakes 32 and 33 both have magnitudes of 3.4, whereas the magnitude estimation of ISC $\left(m_{b}\right)$ is 3.6 and 3.3, respectively.

Based on this relation, we are able to compute magnitude estimates $\mathrm{M}$ for the newly detected earthquakes. For each new earthquake, we compute the amplitude ratio of the detected earthquake with its template. We finally obtain an estimate of the magnitude computing the average of the magnitudes for stations that detected the earthquake. In this study, we do not weight the stations by their computed coherency since all stations have comparable coherency values.

\section{Results}

We found 49 new earthquakes (Data Set S2), of which 28 are foreshocks and 21 are aftershocks (Figure 3a and Data Set S2). The newly detected earthquakes have magnitudes M ranging from 1.9 to 4.8 with a mean value of 3.2 (Figures $3 \mathrm{~b}$ and $3 \mathrm{~d}$ ), that is, below the magnitude of completeness $\approx 3.7$ of the JMA catalog for earthquakes located deeper than $350 \mathrm{~km}$.

The earthquakes we detect follow the Gutenberg-Richter law (Figure S13), and the magnitude of completeness of the new catalog $(\mathrm{Mc})$ is $\approx 2.8$. Following the method of Woessner and Wiemer (2005), we applied different fits to our data set using several magnitudes of completeness to estimate the b-value even though the data set we use is sparse. The $b$-value is constant from the magnitude of completeness of 2.8 to magnitude 4 and is of $0.6 \pm 0.1$ (Figure S14), in agreement with a previous study where b-value was computed for 

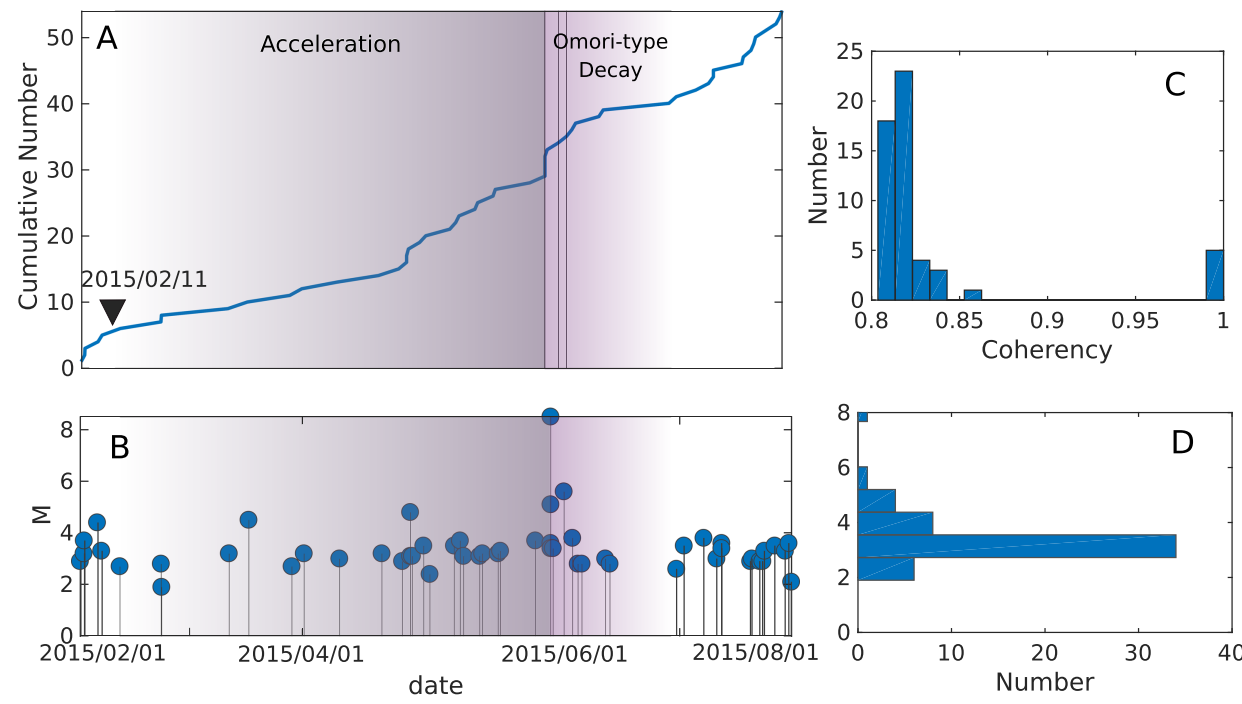

Figure 3. Analysis of the newly detected earthquakes. (a) Cumulative number of earthquakes with time. Vertical lines indicate the origin time of the templates, the first one being the main shock. (b) Magnitude $\mathrm{M}$ versus time of all detected earthquakes. (c) Distribution of the coherency of all the earthquakes. (d) Distribution of the magnitude $\mathrm{M}$ of all the earthquakes.

earthquakes between 500- and 700-km depths (Zhan, 2017). Apart from the detection of the templates with themselves, the coherency value $C$ ranges from 0.81 to 0.86 with a mean value of 0.82 (Figure $3 \mathrm{c}$ ), meaning that no repeating earthquakes (i.e., earthquakes with highly comparable waveforms and which sources overlap, at least partially) were detected as opposed to what has been observed in the Fiji-Tonga (Wiens \& Snider, 2001).

The foreshocks distribution in time is far from being random. On the contrary, it shows a clear change of seismic rate on 11 February 2015 until the occurrence of the main shock (Figure 3), confirming that we detect real earthquakes and not random noise. It can be fitted by an exponential function (with a characteristic time of $\approx 30$ days) or by an inverse Omori-law with $p=1.5$ (Figure 4, black and pink dashed lines, respectively, and Figure S15). Furthermore, following the method described in Bouchon et al. (2013), we obtain a probability of $85 \%$ that this acceleration is not due to chance.

This acceleration disappears when decreasing the coherency threshold, while it becomes clearer for thresholds larger than 0.81 (Figure S16). Looking at the earthquakes with values of $D_{t}<25 \mathrm{~s}$ (Figure 4, purple line),

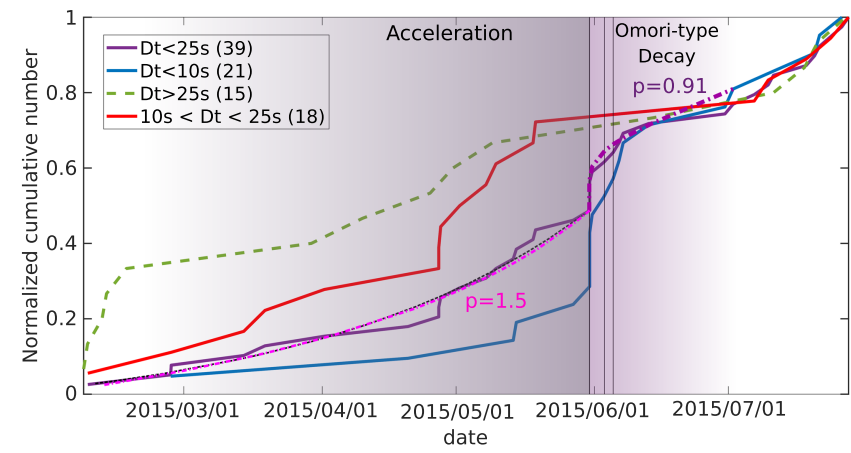

Figure 4. Normalized cumulative number of earthquakes sorted by $D_{t}$ values where $D_{t}$ is the difference between the matrix of arrival times of the template and the detected earthquakes. The total number of earthquakes is given in brackets in the inset. Vertical lines indicate the origin time of the templates. In the acceleration phase, dashed black and pink lines indicate the exponential and Omori-type fit, respectively, of the acceleration phase. In the postseismic phase, the magenta dashed line shows the Omori-decay for aftershocks with $D_{t}<25 \mathrm{~s}$. Earthquakes with $D_{t}$ value between 10 and $25 \mathrm{~s}$ experienced the acceleration phase but not the aftershock decay, showing that the acceleration impacted a larger area than the aftershock sequence. 

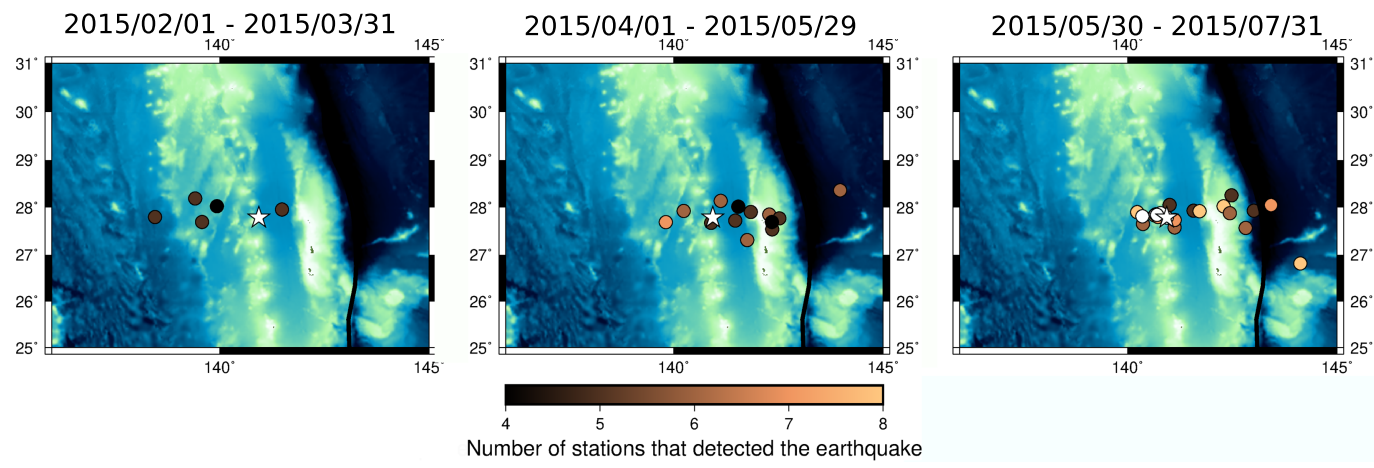

Figure 5. Map view of the reliably located $\left(D_{t}<25 \mathrm{~s}\right)$ detected earthquakes for three time periods, color coded by the number of stations that detected it, as shown by the key at the bottom. The star shows the main shock location. Dates are given as yyyy $/ \mathrm{mm} / \mathrm{dd}$. The two left figures show the migration of the foreshocks towards the east, and the rightmost the 2-month aftershock sequence. White circles are the templates, detected at 58 stations. (Figure S7 shows all the 49 earthquakes.)

the acceleration phase prior to the main shock is also enhanced while it completely disappears for earthquakes with $D_{t}>25 \mathrm{~s}$ (equation (2), Figure 4, dashed, green line). This means that the closer the detected earthquakes are to the templates, the more they are active before the main shock. Indeed, the acceleration phase is very well seen by earthquakes that have a $10 \mathrm{~s}<D_{t}<25 \mathrm{~s}$ (Figure 4, red line), which corresponds to distances of 80 to $200 \mathrm{~km}$ from the templates with a velocity of $8 \mathrm{~km} / \mathrm{s}$. Thus, we will consider only earthquakes with a $D_{t}<25 \mathrm{~s}$ in the following. As increasing the coherency threshold or lowering $D_{t}$ are both equivalent to sharpening the focus within the surroundings of the templates, this phase of preparation is a robust observation, and it is observed for the first time for a deep-focus earthquake and is similar to that seen in laboratory experiments using intact rocks (Lei, 2003; Wang et al., 2017). This is important as it strongly suggests the possible absence of a preexisting fault in the slab. The 21 new aftershocks found in this study follow an Omori-type power-law decay with an exponent $p \simeq 0.91$ (Figure 4, magenta dashed line). The aftershock decay is clearly visible for $D_{t}<25 \mathrm{~s}$ but is more prominent for $D_{t}<10 \mathrm{~s}$. However, the number of aftershocks still remains small for such a large earthquake compared to shallow ones (Frohlich, 2006).

Finally, the temporal distribution of earthquakes according to their $D_{t}$ value indicates that the preseismic phase activated a larger area than the aftershock phase did.

\section{Discussion}

Newly detected earthquakes are located at around $28^{\circ} \mathrm{N}$ latitude (Figure 5) and at a depth close to $700 \mathrm{~km}$ (Figure 6). Because of our network configuration, the resolution in latitude is better than the resolution in longitude (Figure S10) and the location is more reliable for earthquakes detected by a large number of stations (Figure S6). Nevertheless, the seismicity seems to be migrating towards the main shock, within the duration of the acceleration phase (Figure 6, left and middle), while almost all the aftershocks are located east of it (Figure 6, right). The vertical cross section (along AA', Figure 1), reveals a backward bending of the subducting Pacific slab at depth (Figure 6). Such backward bending was also interpreted from recent tomographic imaging (Zhao et al., 2017) and has otherwise only been observed under Indonesia (Schöffel \& Das, 1999). According to thermo-mechanical models of the Izu-Bonin subduction zone (Č́́žková \& Bina, 2015), this bending is consistent with the trench advancing westward (white arrows in Figure 1, Schellart et al., 2007). With this geometry, the eastern part of the slab is also the oldest and coldest, which, from mineral physics, is expected to displace the $660-\mathrm{km}$ discontinuity to greater depths. This would explain both the location of the main shock below $660 \mathrm{~km}$ and the observed longitudinal variations of the discontinuity (Kuge, 2017). This is in good agreement with wave propagation modeling (Castle \& Creager, 1998; Takemura et al., 2016) and with the existence of a "heel part" of the slab hypothesized by Obayashi et al. (2017).

The structure of the slab at depth is debated: a thermal modeling study indicates a buckling of the slab (Yang et al., 2017), while structural modeling suggests a piling up of the slab (Porritt \& Yoshioka, 2016). In any case, source modeling has shown that there is an important deformation at depth causing stress heterogeneity (Chen et al., 2018; Ye et al., 2016). In light of our result, the slab seems to be flat between longitudes $140^{\circ} \mathrm{E}$ 

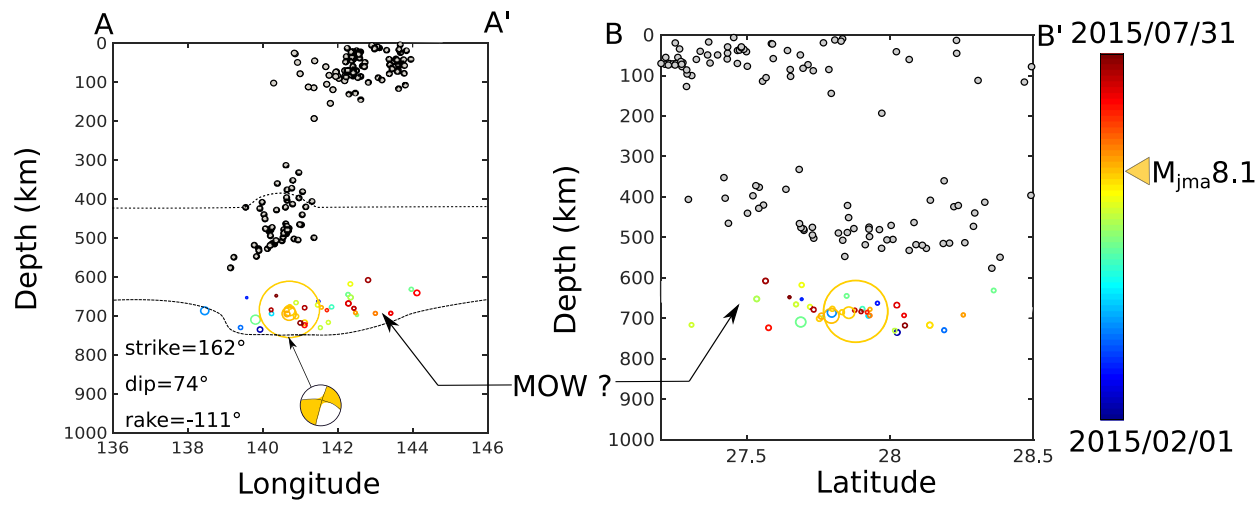

Figure 6. Cross section views of the earthquakes with a $D_{t}<25 \mathrm{~s}$, color coded with time and size proportional to their magnitude $\mathrm{M}$, as shown by the key on the right. Left: along $\mathrm{AA}^{\prime}$; right: along $\mathrm{BB}^{\prime}$. The focal mechanism is the GCMT solution in Figure 1 but in vertical cross section, where $\mathrm{AA}^{\prime}$ and $\mathrm{BB}^{\prime}$ are marked. The locations of the templates and detected earthquakes (open circle) and of the seismicity from the JMA catalog for the analyzed 6 months (grey dots) are shown. Dashed lines indicate the possible 410- and 660-km discontinuities geometries. The green area indicates the possible location of the MOW.

and $144^{\circ} \mathrm{E}$ and 600 - to $700-\mathrm{km}$ depth, which is in good agreement with a recent tomography study (Zhang et al., 2019), but we cannot infer the geometry of the slab at greater depth.

The $\mathrm{BB}^{\prime}$ cross section reveals that the earthquakes all seem located within a 50-km wide band (Figure 6, right). This alignment of microseismicity within a deep and narrow band might be good support for transformational faulting within a MOW. As could be expected for warm slabs (Zhan, 2017), small earthquakes would occur by transformational faulting within the MOW, whereas large ones may nucleate inside of it (also by transformational faulting) but would later expand outside the wedge via alternative frictional weakening mechanisms such as melting (Kanamori et al., 1998) and with decreasing radiation efficiency (Zhan et al., 2014). The seismicity starts where the bending is maximum, where large stress can trigger transformational faulting reactions (Figures 5 and 6).

Acknowledgments

Acknowledgments: Earthquake data were kindly provided by the Japan Meteorological Agency in cooperation with the Ministry of Education,

Culture, Sports, Science and

Technology. We acknowledge the help of the National Research Institute for Earth Science and Disaster Prevention, Tsukuba, for making available their waveform data through their website. We acknowledge support from the European Research Council (grant number 681346-REALISM) and from the 2019 TelluS-ALEA program of the INSU (Institut National des Sciences de l'Univers). We would like to thank Zhongwen Zhan and an anonymous reviewer for very careful reviews of this paper which helped improve and clarify many points. The Editor Gavin Hayes helped us to improve the language and presentation and we are grateful to him for this. Author contributions: BG, AS and SD conceived the study. BG, HLC, DM and MB developed the methods. AK provided additional data. All authors participated to the writing of the manuscript. Competing interests: Authors declare no competing interests. The earthquake catalog data is available in Dataset S2; seismic waveforms used herein are from the National Research Institute for Earth Science and Disaster Resilience http:// www.bosai.go.jp/e/ and we used the Hi-Net stations https://doi.org/10. 17598/NIED.

\section{Conclusion}

In conclusion, our observations suggest that the deep microseismicity in the Izu-Bonin subduction zone is located within a thin MOW whose complex geometry is due to the backward bending of the slab. This area is far from being seismically quiet and shows a relatively intense preseismic phase for the considered depths with a cascading rupture process. This is consistent with recent laboratory experiments on deep earthquakes triggered via transformational faulting (Wang et al., 2017) and, a priori, rules out shear heating thermal runaway as a potential triggering mechanism for the Bonin Islands earthquake. Finally, whereas shallow earthquakes can be preceded by repeating earthquakes (Bouchon et al., 2011; Kato et al., 2012; Kato \& Nakagawa, 2014), no repeaters were detected here. This again supports transformational faulting as the principal mechanism at play as minerals can transform only once.

\section{References}

Bouchon, M., Durand, V., Marsan, D., Karabulut, H., \& Schmittbuhl, J. (2013). The long precursory phase of most large interplate earthquakes. Nature Geoscience, 6, 299-302.

Bouchon, M., Karabulut, H., Aktar, M., Özalaybey, S., Schmittbuhl, J., \& Bouin, M.-P. (2011). Extended nucleation of the 1999 Mw 7.6 Izmit earthquake. Science, 331(6019), 877-880.

Castle, J. C., \& Creager, K. C. (1998). Topography of the 660-km seismic discontinuity beneath Izu-Bonin: Implications for tectonic history and slab deformation. Journal of Geophysical Research, 103(B6), 12,511-12,527.

Chen, Y., Meng, L., Zhang, A., \& Wen, L. (2018). Source complexity of the 2015 Mw 7.9 Bonin earthquake. Geochemistry, Geophysics, Geosystems, 19, 2109-2120. https://doi.org/10.1029/2018GC007489

Čížková, H., \& Bina, C. R. (2015). Geodynamics of trench advance: Insights from a Philippine-Sea-style geometry. Earth and Planetary Science Letters, 430, 408-415.

Ellsworth, W., \& Beroza, G. (1995). Seismic evidence for an earthquake nucleation phase. Science, 268(5212), 851-855.

Frohlich, C. (2006). Deep earthquakes: Cambridge university press.

Frohlich, C., \& Willemann, R. J. (1987). Statistical methods for comparing directions to the orientations of focal mechanisms and Wadati-Benioff zones. Bulletin of the Seismological Society of America, 77(6), 2135-2142. 
Furumura, T., \& Kennett, B. (2005). Subduction zone guided waves and the heterogeneity structure of the subducted plate: Intensity anomalies in northern Japan. Journal of Geophysical Research, 110, B10302. https://doi.org/10.1029/2004JB003486

Furumura, T., \& Kennett, B. L. (2017). Unusual strong ground motion across Japan from the 680 km deep 30 May 2015 Ogasawara Islands earthquake. Journal of Geophysical Research: Solid Earth, 122, 8143-8162. https://doi.org/10.1002/2017JB014519

Gardonio, B., Jolivet, R., Calais, E., \& Leclère, H. (2018). The April 2017 Mw6. 5 Botswana earthquake: An intraplate event triggered by deep fluids. Geophysical Research Letters, 45, 8886-8896. https://doi.org/10.1029/2018GL078297

Gibbons, S., \& Ringdal, F. (2006). The detection of low magnitude seismic events using array-based waveform correlation. Geophysical Journal International, 165, 149-166.

Green II, H., \& Burnley, P. (1989). A new self-organizing mechanism for deep-focus earthquakes. Nature, $341,733$.

Kagan, Y., \& Knopoff, L. (1980). Dependence of seismicity on depth. Bulletin of the Seismological Society of America, 70(5), 1811-1822.

Kanamori, H., Anderson, D. L., \& Heaton, T. H. (1998). Frictional melting during the rupture of the 1994 Bolivian earthquake. Science, 279(5352), 839-842.

Kato, A., \& Nakagawa, S. (2014). Multiple slow-slip events during a foreshock sequence of the 2014 Iquique, Chile Mw 8.1 earthquake. Geophysical Research Letters, 41, 5420-5427. https://doi.org/10.1002/2014GL061138

Kato, A., Obara, K., Igarashi, T., Tsuruoka, H., Nakagawa, S., \& Hirata, N. (2012). Propagation of slow slip leading up to the 2011 Mw 9.0 Tohoku-Oki earthquake. Science, 335(6069), 705-708.

Kelemen, P. B., \& Hirth, G. (2007). A periodic shear-heating mechanism for intermediate-depth earthquakes in the mantle. Nature, 446(7137), 787.

Kirby, S. H. (1987). Localized polymorphic phase transformations in high-pressure faults and applications to the physical mechanism of deep earthquakes. Journal of Geophysical Research, 92(B13), 13,789-13,800.

Kuge, K. (2017). Seismic observations indicating that the 2015 Ogasawara (Bonin) earthquake ruptured beneath the $660 \mathrm{~km}$ discontinuity. Geophysical Research Letters, 44, 10-855. https://doi.org/10.1002/2017GL074469

Lei, X. (2003). How do asperities fracture? An experimental study of unbroken asperities. Earth and Planetary Science Letters, 213(3-4), 347-359.

Lengliné, O., Enescu, B., Peng, Z., \& Shiomi, K. (2012). Decay and expansion of the early aftershock activity following the 2011, Mw9.0 Tohoku earthquake. Geophysical Research Letters, 39, L18309. https://doi.org/10.1029/2012GL052797

McLaskey, G. C., \& Lockner, D. A. (2014). Preslip and cascade processes initiate laboratory stick-slip. Journal of Geophysical Research: Solid Earth, 118, 6323-6336. https://doi.org/10.1002/2014JB011220

Obayashi, M., Fukao, Y., \& Yoshimitsu, J. (2017). Unusually deep Bonin earthquake of 30 May 2015: A precursory signal to slab penetration? Earth and Planetary Science Letters, 459, 221-226.

Passelègue, F., Latour, S., Schubnel, A., Nielsen, S., Suresh, H. B., \& Madariaga, R. (2014). Precursory processes during stick-slip experiments on crustal rocks. AGU Fall Meeting Abstracts, 1(4442), S21B-4442.

Peng, Z., \& Zhao, P. (2009). Migration of early aftershocks following the 2004 Parkfield earthquake. Nature Geoscience, $2,877-881$.

Persh, S. E., \& Houston, H. (2004). Deep earthquake rupture histories determined by global stacking of broadband P waveforms. Journal of Geophysical Research, 109, B04311. https://doi.org/10.1029/2003JB002762

Porritt, R. W., \& Yoshioka, S. (2016). Slab pileup in the mantle transition zone and the 30 May 2015 Chichi-jima earthquake. Geophysical Research Letters, 43, 4905-4912. https://doi.org/10.1002/2016GL068168

Radiguet, M., Perfettini, H., Cotte, N., Gualandi, A., Valette, B., Kostoglodov, V., et al. (2016). Triggering of the 2014 mw7.3 Papanoa earthquake by a slow slip event in Guerrero, Mexico. Nature Geoscience, 9, 829-833.

Schellart, W., Freeman, J., Stegman, D., Moresi, L., \& May, D. (2007). Evolution and diversity of subduction zones controlled by slab width. Nature, 446(7133), 308.

Schöffel, H.-J., \& Das, S. (1999). Fine details of the Wadati-Benioff zone under Indonesia and its geodynamic implications. Journal of Geophysical Research, 104, 13,101-13,114.

Schubnel, A., Brunet, F., Hilairet, N., Gasc, J., Wang, Y., \& Green, H. W. (2013). Deep-focus earthquake analogs recorded at high pressure and temperature in the laboratory. Science, 341(6152), 1377-1380.

Shelly, D., Beroza, G., \& Ide, S. (2007). Non-volcanic tremor and low-frequency earthquake swarms. Nature, 446, $305-307$.

Takemura, S., Maeda, T., Furumura, T., \& Obara, K. (2016). Constraining the source location of the 30 May 2015 (Mw 7.9) Bonin deep-focus earthquake using seismogram envelopes of high-frequency $\mathrm{P}$ waveforms: Occurrence of deep-focus earthquake at the bottom of a subducting slab. Geophysical Research Letters, 43, 4297-4302. https://doi.org/10.1002/2016GL068437

Turner, H. (1922). On the arrival of earthquake waves at the antipodes, and on the measurement of the focal depth of an earthquake. Geophysical Journal International, 1, 1-13.

Vallée, M. (2013). Source time function properties indicate a strain drop independent of earthquake depth and magnitude. Nature Communications, 4, 2606

Wadati, K. (1927). Existence and study of deep-focus earthquakes. Journal of the Meteorological Society of Japan Series II, 5, 119-145.

Waldhauser, F., \& Ellsworth, W. L. (2000). A double-difference earthquake location algorithm: Method and application to the northern Hayward fault, California. Bulletin of the Seismological Society of America, 90(6), 1353-1368.

Wang, Y., Zhu, L., Shi, F., Schubnel, A., Hilairet, N., Yu, T., et al. (2017). A laboratory nanoseismological study on deep-focus earthquake micromechanics. Science Advances, 3(7), e1601896.

Wiens, D. A., \& Snider, N. O. (2001). Repeating deep earthquakes: Evidence for fault reactivation at great depth. Science, 293(5534), $1463-1466$.

Willemann, R. J., \& Storchak, D. A. (2001). Data collection at the International Seismological Centre. Seismological Research Letters, 72(4), 440-453. https://doi.org/10.1785/gssrl.72.4.440

Woessner, J., \& Wiemer, S. (2005). Assessing the quality of earthquake catalogues: Estimating the magnitude of completeness and its uncertainty. Bulletin of the Seismological Society of America, 95(2), 684-698.

Yang, T., Gurnis, M., \& Zhan, Z. (2017). Trench motion-controlled slab morphology and stress variations: Implications for the isolated 2015 Bonin Islands deep earthquake. Geophysical Research Letters, 44, 6641-6650. https://doi.org/10.1002/2017GL073989

Ye, L., Lay, T., Zhan, Z., Kanamori, H., \& Hao, J.-L. (2016). The isolated 680 km deep 30 May 2015 Mw 7.9 Ogasawara (Bonin) Islands earthquake. Earth and Planetary Science Letters, 433, 169-179.

Zhan, Z. (2017). Gutenberg-Richter law for deep earthquakes revisited: A dual-mechanism hypothesis. Earth and Planetary Science Letters, $461,1-7$. 
Zhan, Z., Kanamori, H., Tsai, V. C., Helmberger, D. V., \& Wei, S. (2014). Rupture complexity of the 1994 Bolivia and 2013 Sea of Okhotsk deep earthquakes. Earth and Planetary Science Letters, 385, 89-96.

Zhang, H., Wang, F., Myhill, R., \& Guo, H. (2019). Slab morphology and deformation beneath Izu-Bonin. Nature communications, 10(1), 1310 .

Zhao, D., Fujisawa, M., \& Toyokuni, G. (2017). Tomography of the subducting Pacific slab and the 2015 Bonin deepest earthquake (Mw 7.9). Scientific reports, 7, 44487. 